\title{
COUNTRY PROFILE \\ Achievements and challenges in psychiatric education and training in Sri Lanka
}

\author{
Aruni Hapangama, ${ }^{1} \odot$ K.A.L.A. Kuruppuarachchi ${ }^{2}$ and Raveen Hanwella ${ }^{3}$
}

${ }^{1}$ FRANZCP, Senior Lecturer, Department of Psychiatry, Faculty of Medicine, University of Kelaniya, Sri Lanka. Email: ahapangama@kln.ac.lk

${ }^{2}$ FRCPsych, Cadre Chair and Senior Professor of Psychiatry. Department of Psychiatry, Faculty of Medicine, University of Kelaniya, Sri Lanka

${ }^{3}$ FRCPsych, Cadre Chair and Senior Professor of Psychiatry, Department of Psychiatry, Faculty of Medicine, University of Colombo, Sri Lanka

Keywords. Psychiatry; undergraduate curriculum; internship; challenges; South Asia.

First received 7 Apr 2021 Final revision 3 Jun 2021 Accepted 4 Jun 2021

doi:10.1192/bji.2021.35

(c) The Author(s), 2021. Published by Cambridge University Press on behalf of the Royal College of Psychiatrists. This is an Open Psychiatists. This is an Open Access article, distributed und the terms of the Creative Commons Attribution licence (http://creativecommons.org/ licenses/by/4.0/), which permits unrestricted re-use, distribution, and reproduction in any medium, provided the original work is properly cited.
When compared with other Asian countries, psychiatric education and training in Sri Lanka has made significant developments during the past two decades, such as introducing psychiatry as a separate final year subject in the undergraduate medical curricula. However, further developments in psychiatric training in medical education are needed.

Sri Lanka recorded a disability-adjusted life-year rate (per 100000 population) of 2800.82 in 2017 , ${ }^{1}$ but one of the biggest challenges in meeting the needs of people with mental illnesses has been the severe shortage of trained human resources: for example, the country has only 0.52 consultant psychiatrists per 100000 of the population. $^{2,3}$

\section{Undergraduate psychiatry education}

Before the year 2000, undergraduate psychiatric teaching in Sri Lanka was limited to lectures and clinical attachments in the third and/or fourth years and a few tutorials in the final year. What was taught in those 3 years was assessed only at the final MBBS examination and limited to one structured essay question and a couple of multiple-choice questions in the medicine paper. However, with the landmark efforts of the University of Colombo, psychiatry was introduced as a final year subject with a separate paper. The other state universities followed, and some universities also introduced basic psychology lectures during the first 2 years of the medical curriculum.

Another significant achievement was the approval of the co-curriculum in psychiatry by the University Grants Commission of Sri Lanka. This is now adopted by all state universities, unifying teaching and assessments across the universities.

Since 2018, psychiatry has been a final year subject considered for the merit list for internship with the other four major clinical specialties: clinical medicine, surgery, obstetrics and gynaecology, and paediatrics. This has been a crucial and important step that would motivate students to study psychiatry. In addition, shifting of the core clinical teaching in psychiatry to the final year in Sri Lankan state universities gives students the opportunity of concurrent learning of psychiatry with the other four disciplines. It also emphasises the relationship between the five specialties and enables students to understand better the liaison model of psychiatry and the importance of mental health issues in all clinical specialties. Increasing the clinical training in psychiatry during the undergraduate years will improve students' clinical competency in diagnosing mental illnesses and helps development of core soft skills such as listening, empathy, effective communication and humanitarian values. ${ }^{4} \mathrm{~A}$ study done among students of a state medical school showed that the knowledge and attitudes of the medical students towards psychiatry changed after introduction of the new curricula and the expansion of the undergraduate training programme in psychiatry. ${ }^{5}$

\section{Postgraduate education in psychiatry}

A medical officer who passes the selection examination enters the MD training programme in psychiatry conducted by the Postgraduate Institute of Medicine, University of Colombo. The MD programme in psychiatry runs for 3 years and those who get through their MD examination can train in an approved centre overseas, as part of the medical training initiative (MTI) programme of the UK or a hospital-sponsored placement in Australia.

In the past, retention of psychiatric trainees in Sri Lanka had been a significant problem, as the country lost most of its psychiatry trainees, who for many personal reasons did not return from their overseas training. ${ }^{6}$

However, reports show that, in addition to increasing numbers of candidates sitting the selection examination for a MD in psychiatry, there is an encouraging trend with most trainees who had gone for overseas training to return home. ${ }^{7}$

\section{Postgraduate diploma in psychiatry}

In 2007, to mitigate the treatment gap due to the lack of qualified specialists, the Postgraduate Institute of Medicine at the University of Colombo introduced a new psychiatry programme. This programme comprises a 1-year training course, leading to a diploma in psychiatry. Diploma holders serve mostly in out-patient clinics under the supervision of a consultant psychiatrist.

\section{Continuing professional development} opportunities for board-certified specialists

Currently, besides self-guided learning, the Sri Lanka College of Psychiatrists provides an 
informal continuing professional development programme.

\section{Training of specialists in other disciplines}

Board-certified specialists in psychiatry are invited to provide teaching and learning activities for postgraduate trainees in medicine and family medicine. Trainees in medicine and family medicine also have to undergo short appointments in clinical psychiatry.

\section{Areas that need improvement Internship in psychiatry}

The main aim of a medical curriculum is to train a person to effectively manage a patient at the level of a family practitioner and give a grounding in the main clinical specialties that will be retained even after doctors with the basic medical degree specialise in their fields of interest. The internship is the key to the transition from being a medical undergraduate to a practising doctor.

Currently in Sri Lanka, graduating doctors can choose two specialties from the four traditional main clinical specialties and train as an intern for 6 months in each of the two selected. Psychiatry is not an option yet. This is neither logical nor prudent. Both Australia and the UK have moved away from the traditional apprenticeship model of internship and have structured programmes with clear learning objectives. ${ }^{8,9}$

The Medical Board of Australia, which sets a broad structure for internship training in Australia, requires a total duration of 47 weeks of full-time or equivalent training. ${ }^{8}$ Interns need to complete at least 10 weeks each in medicine and surgery, and at least 8 weeks in emergency medical care. They can spend the rest of the time in a range of specialties, including psychiatry and general practice.

In the UK too, Foundation Year 1 has replaced the traditional internship year. ${ }^{9}$ The trainee doctor is expected to complete 20 'foundation professional capabilities', including knowledge, skills and behaviours, and to meet a minimum standard. The propotion of psychiatry has gradually being increased as per the 2016 foundation programme curriculum. ${ }^{9}$

A World Health Organization policy paper estimates that by 2030, the leading global disease burden will be untreated mental health problems (13\%), particularly depression, and mental illness will be the principal cause of mortality and morbidity globally. ${ }^{10}$ In addition, psychiatrists or doctors with some mental health expertise will be expected to manage the behavioural and psychiatric problems of patients with dementia, self-harm and substance use problems. It will be crucial that all doctors in Sri Lanka have a minimal level of competence in managing these issues. Although having psychiatry as a final year merit subject is a major step, this is not sufficient. To ensure that a doctor gets practical experience in managing these common psychiatric and mental health problems, a period of practical training after medical school would be vital. An internship will be a valuable option to ensure these objectives. We propose an internship in psychiatry of 6 months added to the current mandatory internship period of one year. The intern can choose between psychiatry or other clinical specialties such as ear, nose and throat (ENT), ophthalmology, dermatology, emergency medicine, family medicine or community-based disciplines during this period. We postulate that those who are already interested in psychiatry will take up psychiatry and the internship will consolidate the skills gained during their final year. In addition, making this particular rotation elective would also minimise problems in finding an adequate number of supervisors and units where they can be placed, as some hospitals currently do not have adequate infrastructure.

A principal objection to the proposal would be the lengthening of the period of internship. However, this might be overcome to some extent by incentives such as naming the extended period a senior internship, with a corresponding increase in salary.

We also propose a more objective and structured assessment of a doctor's performance in internship than a signature by the consultant.

Despite a heavy burden of psychiatric morbidity, the only South Asian country to offer internship in psychiatry is India, where medical students complete a 2-week mandatory psychiatry internship. ${ }^{11}$ If Sri Lanka is to take up this pioneering role and assess its feasibility and success, other low- and middle-income countries may follow similar or modified models depending on their resources. Psychiatrists have to play a large role in convincing medical regulatory bodies and other stakeholders of the need for this proposed model.

\section{Training in research methodology}

Another area that needs urgent attention is encouraging and training in research methodology related to psychiatry. ${ }^{12}$ There is a significant lack of funds for research in mental health in Sri Lanka and it is time that authorities allocate sufficient funds to increase the research capacity.

\section{Conclusions}

Although the Sri Lankan psychiatric fraternity can be proud of their achievements in terms of educational and training needs, we need to be mindful that psychiatry is no longer an isolated discipline, and proper education and training of future medical practitioners will have widespread and critical health and economic implications.

\section{Author contributions}

A.H., K.A.L.A.K. and R.H. contributed equally to the literature survey and the writing of the manuscript. 


\section{Funding}

This article received no specific grant from any funding agency, commercial or not-for-profit sectors.

\section{Declaration of interest}

None.

\section{References}

1 World Health Organization. Mental Health ATLAS 2017 Member State Profile. WHO (http://www.who.int/mental_health/ evidence/atlas/profiles-2017-LKApdf?ua=1).

2 Bruckner TA, Scheffler RM, Shen G, Yoon J, Chisholm D, Morris J, et al The mental health workforce gap in low- and middle-income countries: a needs-based approach. Bull World Health Organ 2011; 89: 184-94.

3 World Health Organization. Mental Health ATLAS 2017 Member State Profile. WHO, 2017 (https://www.who.int/ mental_health/evidence/atlas/profiles-2017/LKA.pdf?ua=1).

4 Kallivayalil RA. The importance of psychiatry in undergraduate medical education in India. Indian J Psychiatry 2012; 54 : 208-16.

5 Rodrigo A, Wijesinghe C, Kuruppuarachchi K. Changes in attitudes toward psychiatry with introduction of a new curriculum: experiences of a Sri Lankan medical school. Sri Lanka J Psychiatry 2012; 3: 14-6.

6 Kuruppuarachchi KALA. Recruitment and retention of psychiatrists in low-income countries. Psychiatr Bull 2008; 32: $154-5$

7 Kathriarachchi ST, Seneviratne VL, Amarakoon L. Development of mental health care in Sri Lanka: lessons learned. Taiwan J Psychiatry 2019; 33: 55-65.

8 Australia Medical Council. Guide to Intern Training in Australia. AMC, 2018 (https://www.amc.org.au/wp-content/uploads/2018/ 12/Guide-to-Intern-Training.pdf)

9 Health Education England. The Foundation Programme Curriculum 2016. Health Education England, 2016.

10 Rehm J, Shield KD. Global burden of disease and the impact of mental and addictive disorders. Curr Psychiatry Rep 2019; 21(2): 10.

11 Reddy S, Reddy P, Mishra K. Impact of duration of psychiatry rotation on medical interns' attitude towards psychiatry. J Psychiatry Allied Sci 2017; 8: 18-23.

12 Siriwardhana C, Sumathipala A, Siribaddana S, Samaraweera $S$, Abeysinghe $N$, Prince $M$, et al Reducing the scarcity in mental health research from low- and middle-income countries: a success story from Sri Lanka. Int Rev Psychiatry 2011; 23: 77-83.
MENTAL HEALTH LAW PROFILE

\title{
Why are we still living in the past? Sri Lanka needs urgent and timely reforms of its archaic mental health laws
}

\author{
Aruni Hapangama, ${ }^{1} \odot$ Jayan Mendis ${ }^{2}$ and K.A.L.A. Kuruppuarachchi ${ }^{3}$
}

${ }^{1}$ FRANZCP, Professor in Psychiatry Department of Psychiatry, Faculty of Medicine, University of Kelaniya, Ragama, Sri Lanka. gama@kln.ac.lk

${ }^{2}$ MDpsych, Senior Lecturer, Department of Psychiatry, General Sir John Kotelawala Defence University, Ratmalana, Sri Lanka ${ }^{3}$ FRCPsych, Cadre Chair and Senior Professor of Psychiatry, Department of Psychiatry, Faculty of Medicine, University of Kelaniya, Ragama, Sri Lanka

Keywords. Mental health act: human rights; Sri Lanka; South Asia; mental diseases.

First received 28 Jan 2022 Final revision 1 Jul 2022 Accepted 1 Aug 2022

\section{doi:10.1192/bji.2022.26}

(c) The Author(s), 2022. Published by Cambridge University Press on behalf of the Royal College of Psychiatrists. This is an Open Acchess article, distributed unde Access article, distributed
the terms of the Creative Commons Attribution licence (http://creativecommons.org/ licenses/by/4.0/), which permits unrestricted re use, distribution and reproduction, provided the original article is properly cited.
Mental health legislation protects the rights of people with mental illnesses. However, despite major social, political and cultural changes, Sri Lankan mental health services still operate on laws enacted mostly during the British rule more than a century ago, in the pre-psychotropics era, and focusing more on the detention of people with mental illnesses than on their treatment. It is high time all stakeholders made efforts for the much-awaited new Mental Health Act to pass through parliament urgently to meet the needs and protect the rights of patients, their caregivers and service providers.

People with mental illnesses face stigma, discrimination, marginalisation and violation of their rights; furthermore, owing to the nature of symptoms some have impaired decision-making capacity, which may result in refusal to accept treatment. ${ }^{1,2}$

In 2017 Sri Lanka, with its population of more than 21 million, was reported to have 2800.2 disability-adjusted life years due to mental illnesses per 100000 population; ${ }^{3}$ the rate of suicides per 100000 population was $14.6 .{ }^{4}$ However, Sri Lanka not only lacks enough trained clinicians (e.g. there were 0.52 psychiatrists per 100000 population in 2017) to meet this disease burden but it also does not have up-to-date laws to govern them to provide care for people with mental illnesses in the least restrictive and least intrusive manner. ${ }^{2}$

Sri Lanka, which is proud of its free health services and vastly improving healthcare indices, still operates on mental health laws that were first formulated in 1873, when the country was a colony of the UK, whereas some of the other South Asian countries, such as India and Pakistan, who also inherited their mental health laws from the UK, have enacted new laws (in 2017 and 2001 respectively) in concordance with the United Nations Convention on the Rights of Persons with Disabilities. ${ }^{5-8}$ Sri Lanka lags far behind its South Asian neighbours with its 'new Mental Health Act' being in draft status since the early 2000s. ${ }^{9}$

Sri Lanka's Lunacy Ordinance of 1873 has undergone several amendments, the last of which was back in 1956, when it was renamed the Mental Diseases Ordinance (also known as the Mental Diseases Act). ${ }^{5,10}$ This act abolished 